\title{
Development of a Water Budget Management System for Fire Potential Mapping
}

\author{
Jinmu Choi \\ Department of Geosciences, Mississippi State University, P.O. Box 5448, \\ Mississippi State, Mississippi 39762
}

\author{
William H. Cooke ${ }^{1}$ \\ Department of Geosciences and GeoResource Institute, Mississippi State \\ University, PO Box 5448, Mississippi State, Mississippi 39762
}

\author{
Mark D. Stevens \\ NVision Solutions, Inc., 13131 Hwy 603, Suite 304, Bay St. Louis, \\ Mississippi 39520
}

\begin{abstract}
A water budget is important for environmental models such as a fire potential model. For the eastern United States, water budget indices derived from the cumulative interplay of precipitation and evaporation characterizes moisture conditions better than the Keech-Byram drought index. Because there are various sources of precipitation and evaporation data, it is difficult to manage those data consistently through time in order to derive cumulative water budget indices. In this study, we developed a water budget management system (WBMS) that downloads climate data and calculates a water budget. A geodatabase was designed to support the WBMS. Finally, the WBMS was tested for mapping fire potential in Mississippi.
\end{abstract}

\section{INTRODUCTION}

Daily water budget calculations are important for development of a dynamic variable that should be considered for modeling fire potential, making crop management decisions, and for other applications focusing on water management and conservation (Cooke et al., 2008). In particular, fire potential modeling is an example of an environmental model in which climate data play an important role. Much of the existing literature on fire potential modeling in the U.S. is oriented toward the western U.S. (Morgan et al., 2001), which utilizes the Keech-Byram drought index (KBDI) as an indicator of landscape moisture condition. Although indices like KBDI are often used (Texas Forest Service, Wildland Fire Assessment System [WFAS], etc.) to estimate fire potential, the usefulness of KBDI alone for determining fire potential in the eastern United States has not been documented in the literature.

\footnotetext{
${ }^{1}$ Corresponding author; email: whe@geosci.msstate.edu
} 
Morris (2007) tested the usefulness of KBDI alone as a measure of fire potential and found that KBDI was a poor predictor of forest fire risk potential in southern Mississippi. The regression results of fire occurrence and KBDI indicated poor model fit, and very little of the variance in fire frequency or fire size was explained by KBDI $\left(R^{2}=.048\right.$ and .066 respectively). Therefore, daily water budget indices instead of KBDI were derived to represent landscape moisture for the southeastern U.S.

The daily water budget can be calculated by expressing the interplay of precipitation and evaporation. There are two common sources for precipitation data: weather station data and interpolated Doppler (NEXRAD: Next-Generation Radar) radar estimates. $^{2}$ In Mississippi, precipitation data are provided at only 26 weather stations that are located in the eastern and southern areas of the state. On the other hand, NEXRAD radar estimates of daily precipitation are recorded at $4 \mathrm{~km}$ intervals across the state on the Hydrologic Rainfall Analysis Project (HRAP) point grid. Estimated precipitation at high spatial densities $(4 \mathrm{~km})$ offers increased spatial precision necessary for recording the relatively small convective weather events that are characteristic of summer weather conditions. According to the Statements of Guidance (SOGs) provided by the World Meteorological Organization, ${ }^{3}$ quantitative precipitation observations from satellite measurements (e.g. data from TRMM satellite) do not meet accuracy requirements (WMO, 2008). The SOGs also stated that "Precipitation depth and type are routinely observed on an hourly to daily basis at synoptic weather stations but there are large regional differences in coverage; spatial and temporal coverage of rainfall observations is improving using ground radar techniques." The statement supports our adoption of NEXRAD data for precipitation estimates.

Acquisition of pan evaporation data for water budget calculations is also a challenge due to sparse spatial distribution of measurement devices and concerns regarding data accuracy. Because evaporation pans and automated measurement devices are expensive, the National Weather Service maintains evaporation pans at a limited number of weather stations around the U.S. (Jones, 1992). For example, in Mississippi relatively few evaporation pans are maintained and most are in the northern twothirds of the state (Bell, 2004). In addition to the relative scarcity of the evaporation measurement devices, the accuracy of pan evaporation estimates has been questioned by numerous researchers (e.g., Bruton et al., 2000; Sumner and Jacobs, 2005). In addition, precipitation events interfere with accurate measurement of pan evaporation (Lindsey and Farnsworth, 1997). Errors in rainfall measurement and inconsistency in rainfall capture add error to recorded pan evaporation data (Sumner and Jacobs, 2005). To solve these obstacles in pan evaporation estimates, Cooke et al. (2008) suggested a regression model for estimating pan evaporation for the southeastern U.S., a method that was applied in this study

Although previous studies provide enhanced methodologies for accurately estimating precipitation and evaporation, water budget calculations are still a labor-intensive process because of the need to integrate data from multiple sources, different data types, different map projections, and the difficulty of maintaining and accumulating

\footnotetext{
${ }^{2}$ Multi-Sensor Precipitation Estimates (MPE) data from NEXRAD radar are provided by the National Oceanic and Atmospheric Administration Hydrologic Data Systems Group and are available at their website (http://dipper.nws.noaa.gov/hdsb/data/nexrad/nexrad.html).

${ }^{3}$ More information is available at www.wmo.int/pages/index_en.html.
} 
precipitation and evaporation data. Therefore, in this study, a water budget management system (WBMS) was developed to automate water budget data management from downloading data to deriving water budget indices that are directly used in environment models. To store the spatio-temporal climate data, ESRI's geodatabase was used in the WBMS.

The developed WBMS was then tested for use in fire potential models developed for the state of Mississippi. Fire is of ecological and economic importance in the United States, and fire frequency data obtained from the Mississippi Forestry Commission (MFC) indicates that on average, for a 15 -year period beginning in 1990, fire personnel were dispatched to over 3,700 fires per year (Cooke et al., 2007). Decisions regarding fire response and suppression, and personnel and equipment staging, prescribe burning for fuel reduction, and implementation of burn bans could benefit from spatio-temporal depictions of fire potential.

In the next section of this paper ("Methods"), the cumulative interplay of precipitation and evaporation was examined to help characterize various landscape moisture conditions in the eastern U.S. as an alternative to KBDI. The water budget index was derived by comparing daily water budget assessments with 50-year historic water budget data. In a third section ("Water Budget Management System"), the design and implementation of the WBMS is discussed. The design of a geodatabase was included to facilitate understanding of the approach used to store and automate calculations performed with climate data. In the fourth section ("Mapping Fire Potential"), the use of WBMS for mapping fire potential for Mississippi is discussed. Key issues are summarized in the concluding section.

\section{METHODS}

\section{Water Budget Calculation}

The interaction of precipitation (P) and evaporation (E) helps to characterize landscape moisture. This study derives water budget estimates using daily assessments of precipitation and evaporation. Precipitation values were derived from Doppler radar-based estimates of hourly rainfall accumulation, available on the HRAP grid. Evaporation values were estimated from weather station observations using regression models of temperature and humidity (Cooke et al., 2008).

A more accurate water budget could be calculated using evapotranspiration instead of evaporation. However, data necessary for evapotranspiration calculation is often not available. For example, the Penman-Monteith equation, a commonly used estimator of evapotranspiration (Monteith, 1965), requires measurement of solar radiation, air temperature, relative humidity, wind speed, and other vegetation-specific parameters (i.e., stomatal resistance or conductance) (Beven, 1979). A complete set of these input elements at locations that are spatially well distributed over large areas is rare. For example, of 178 weather stations in Mississippi, only 17 stations consistently record solar radiation (Cooke et al., 2008). To derive the water budget index we used evaporation to insure consistency with the historic cumulative P-E. Therefore, this study adopted regression-based evaporation estimation (Cooke et al., 2008). Evaporation estimates were subtracted from precipitation to compute a daily cumulative water budget. 


\section{NEXRAD Doppler Radar-Based Precipitation Estimates}

Until 2006, NEXRAD radar data were available in the form of binary files that contained hourly values over an entire region. For modeling purposes, the precipitation data must be accumulated every 24 hours to match the temporal resolution of the daily evaporation data. The radar data are presented in a binary format (XMRG) in the HRAP coordinate system. Each data file begins with a header that contains the origin, number of columns and rows represented in the file, and other metadata. In the body of the file, data is presented in rows and columns. A point's location in the XMRG file is directly related to its HRAP coordinate. For example, if the origin in the file header is $(100,100)$, then a point in column 30 , row 15 has HRAP coordinates of $(130,115)$.

Beginning in 2007, however, radar data became available in shapefile format. Therefore, it is no longer necessary to read binary files and determine HRAP coordinates. A precipitation shapefile can be directly imported into the precipitation class in a geodatabase.

\section{Regression for Evaporation}

Precipitation $(\mathrm{P})$ is a critical fuel moisture component in a fire potential model, but high temperatures in Mississippi are associated with high rates of evaporation (E). Including evaporation in water budget calculations is important when determining available moisture in the environment. Pan evaporation stations that provide evaporation data exist, but are sparsely distributed across the southeastern United States. Therefore, in this study, evaporation data were estimated by Cooke et al.'s (2008) regression models for inland and coastal locations, which characterize the lower and higher humidity environments of the landscape, respectively. Three linear regression models were constructed and validated using minimum daily relative humidity, maximum daily temperature, and total daily solar radiation data acquired at several pan evaporation locations (Fig. 1). Observation station networks for predicting evaporation consisted of 178 weather stations integrated from the National Weather Service, the Louisiana Agriclimatic Information Center, ${ }^{4}$ the Mississippi State University Extension Service, ${ }^{5}$ and the University of Utah's "Meso West" weather service ${ }^{6}$ (Cooke et al., 2008). In Figure 1, the best inland model (BIM) was applied to predict evaporation when solar radiation data were available for which only 17 of 178 stations were recording solar radiation. If a weather station only recorded relative humidity and temperature, an optional inland model (OBIM) was applied for the weather station. For the coastal areas, the best coastal model (BCM) was applied to predict evaporation.

Weather station observation (evaporation) data were delivered as ASCII files that can contain daily observations for specified periods of time. This study utilized maximum temperature and minimum relative humidity to estimate evaporation based

\footnotetext{
${ }^{4}$ Information available at http://www.lsuagcenter.com/weather/

${ }^{5}$ Information available at http://ext.msstate.edu/anr/drec/

${ }^{6}$ Information available at http://www.met.utah.edu/mesowest/
} 

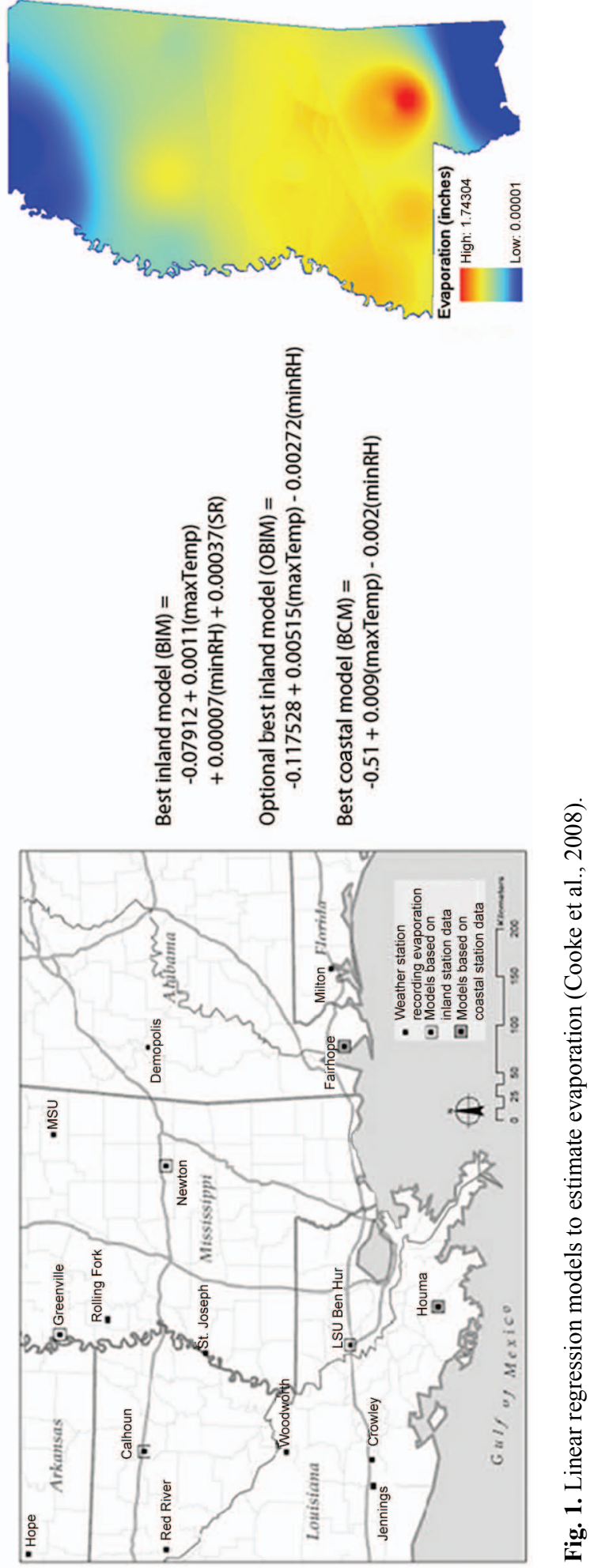
on station_ID and date. Weather station location data (latitude and longitude) were extracted from the header information of each weather station data file.

\section{Water Budget (P-E) Index Calculation}

Daily water budget estimates were calculated by accumulating daily precipitation minus evaporation (P-E) estimates (Fig. 2A). Historic water budget estimates were interpolated from historic water budget point data (Fig. 2B). Daily water budget estimates were then compared to the historic water budget. The water budget variable is an index that was calculated by measuring the daily departure of P-E from the historic P-E averages (Fig. 2C). While not a direct measure of the water budget, this index is representative of landscape moisture conditions (i.e., how wet or dry the current conditions are compared to the historic average water budget). For fire potential modeling, the spatial depiction of cumulative wet or dry landscape conditions, used in conjunction with vegetation (fuels) information and ignition probability. provide both a spatial and temporal view of patterns of fire potential.

\section{WATER BUDGET MANAGEMENT SYSTEM}

\section{Framework of the Water Budget Management System}

The water budget management system (WBMS) is a stand-alone application designed to facilitate climate data management and to calculate a daily cumulative water budget for the state of Mississippi (Fig. 3). The WBMS has three main modules: (1) climate (precipitation and evaporation) data import; (2) climate data accumulation and water budget index calculation; and (3) fire potential mapping. The climate data import module automates downloading of climate data from the website, ${ }^{7}$ data formatting, HRAP coordinate transformation, loading the data into a geodatabase, and deleting all intermediate files. Because the water budget (P-E) is cumulative in nature, it is necessary to accumulate the climate (precipitation and evaporation) data over various temporal periods. The water budget index is then derived by comparing the accumulated water budget with the 50-year historic water budget in the water budget calculation module. The resulting data are then stored into a geodatabase. Finally, the water budget index in the geodatabase can be used for the fire potential mapping.

\section{Geodatabase Design for Spatio-temporal Climate Data}

To manage spatio-temporal climate data, this study adopted the ESRI geodatabase design (Fig. 4) that contains four types of data: point features, observations, time, and regression information. Feature classes include radar sample points (radarLocation) and weather station location (StationLocations). Two object classes store radar data (radarObservation) and weather station data (StationObservations) that are

\footnotetext{
${ }^{7}$ The website of the NEXRAD Radar for precipitation is http://www.srh.weather.gov/rfcshare/ p_download. The website of the MesoWest for evaporation is http://www.met.utah.edu/cgi-bin/droman/ mesomap.cgi?state $=$ MS\&rawsflag $=3$
} 

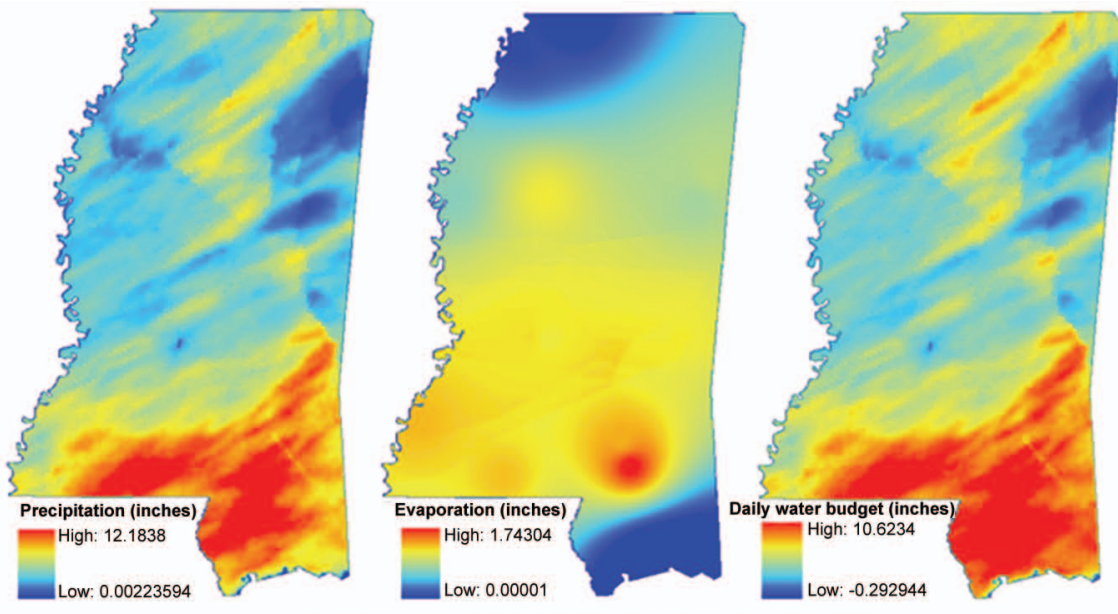

A. Daily water budget (P - E) for January 2008

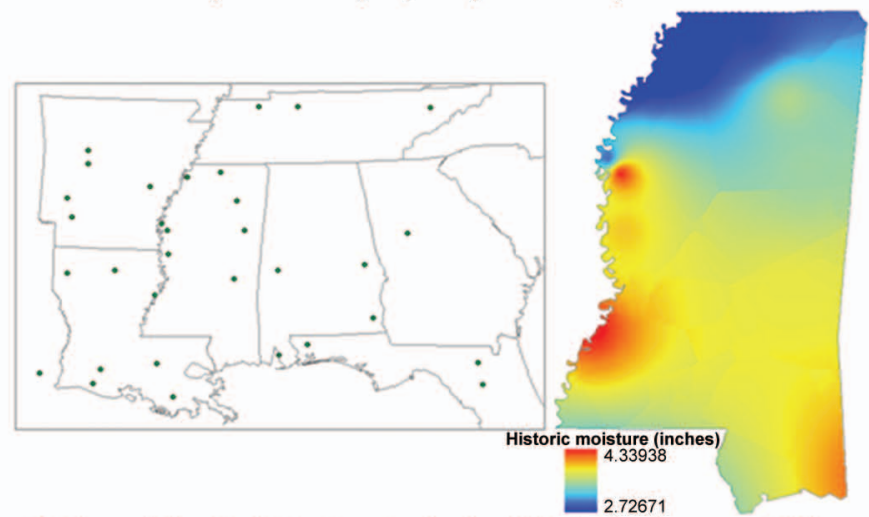

B. Interpolation for historic water budget (P - E) for January 2008
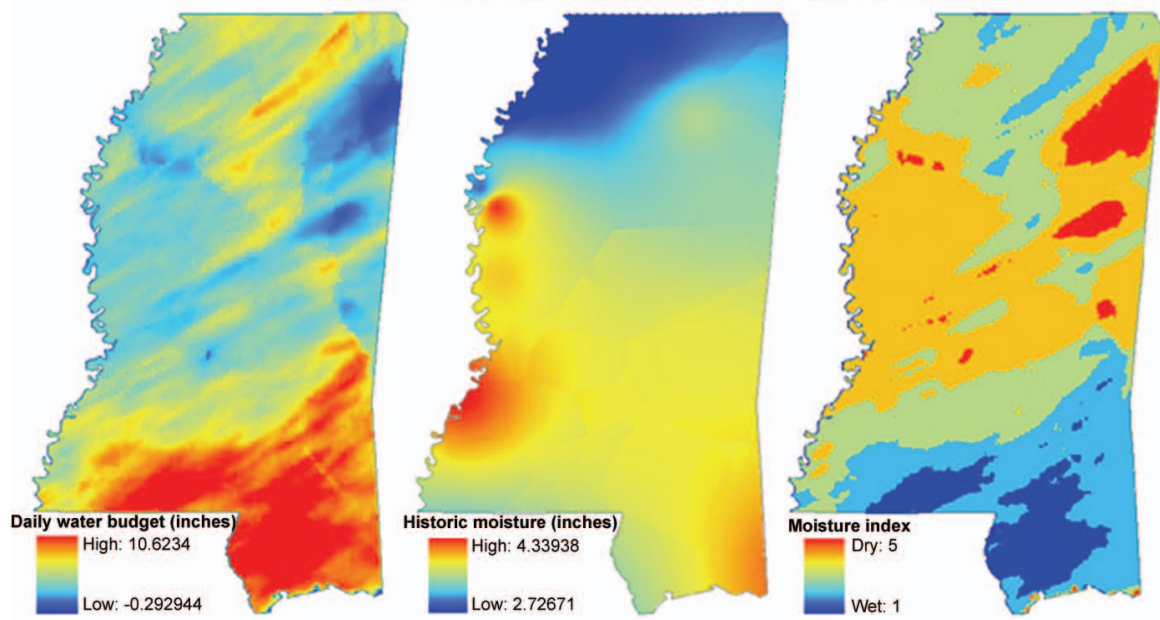

C. Water budget $(P-E)$ index for January 2008

Fig. 2. Example of water budget (P - E) index calculation for January 2008. 


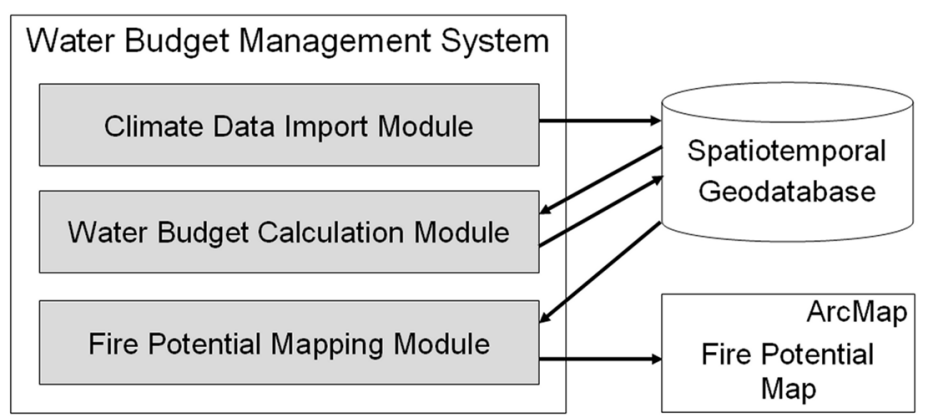

Fig. 3. Framework of the water budget management system (WBMS).

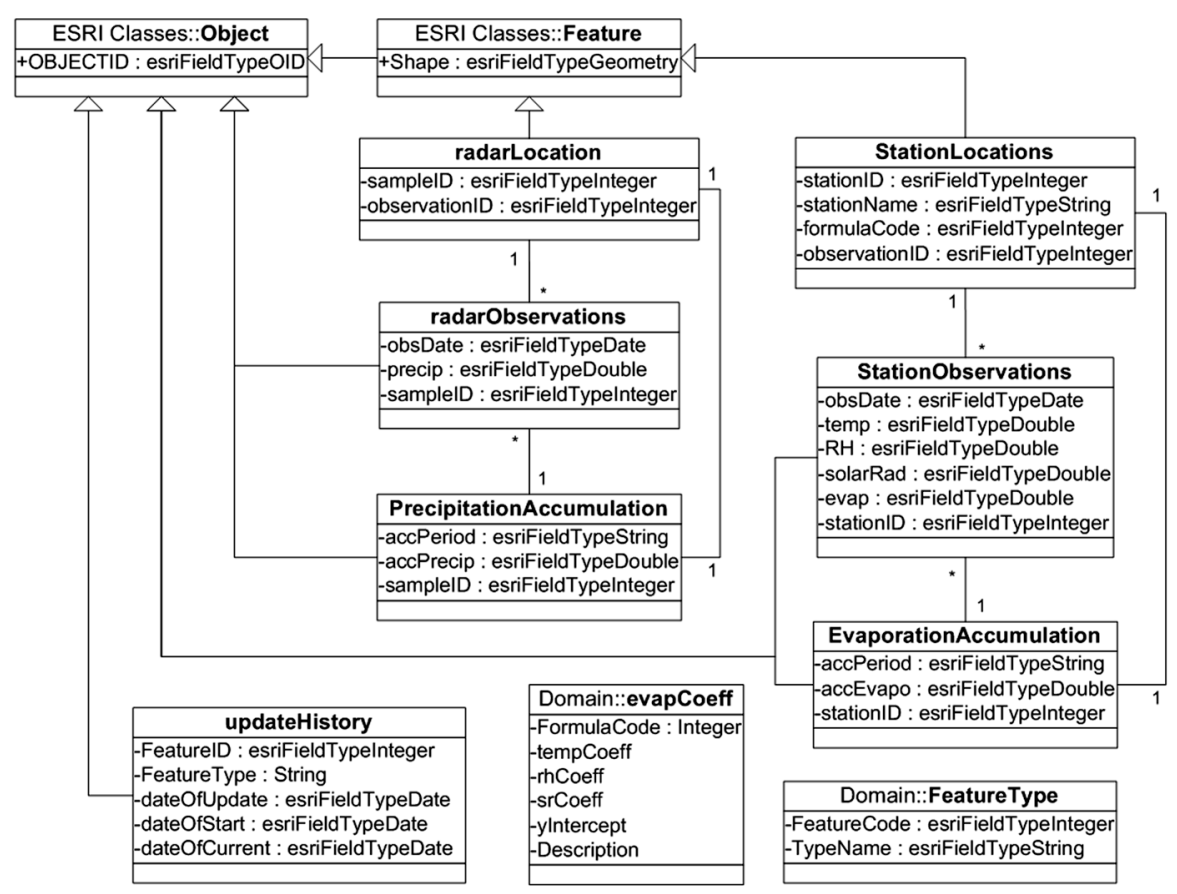

Fig. 4. UML geodatabase model for climate data management.

related to the corresponding feature table based on measurement time in the time table (UpdateHistory table). The relationship is a one-to-many relationship between the location feature class and the observation object class. While transaction time is stored in the dateofUpdate field in the updateHistory table, the real data collection time is stored in the dateofStart and dateofCurrent fields as well as in the updateHistory table. Precipitation and evaporation are accumulated based on the time period chosen by the user and stored in the accumulation tables, PrecipitationAccumulation and EvaporationAccumulation. These tables are related to the corresponding feature 


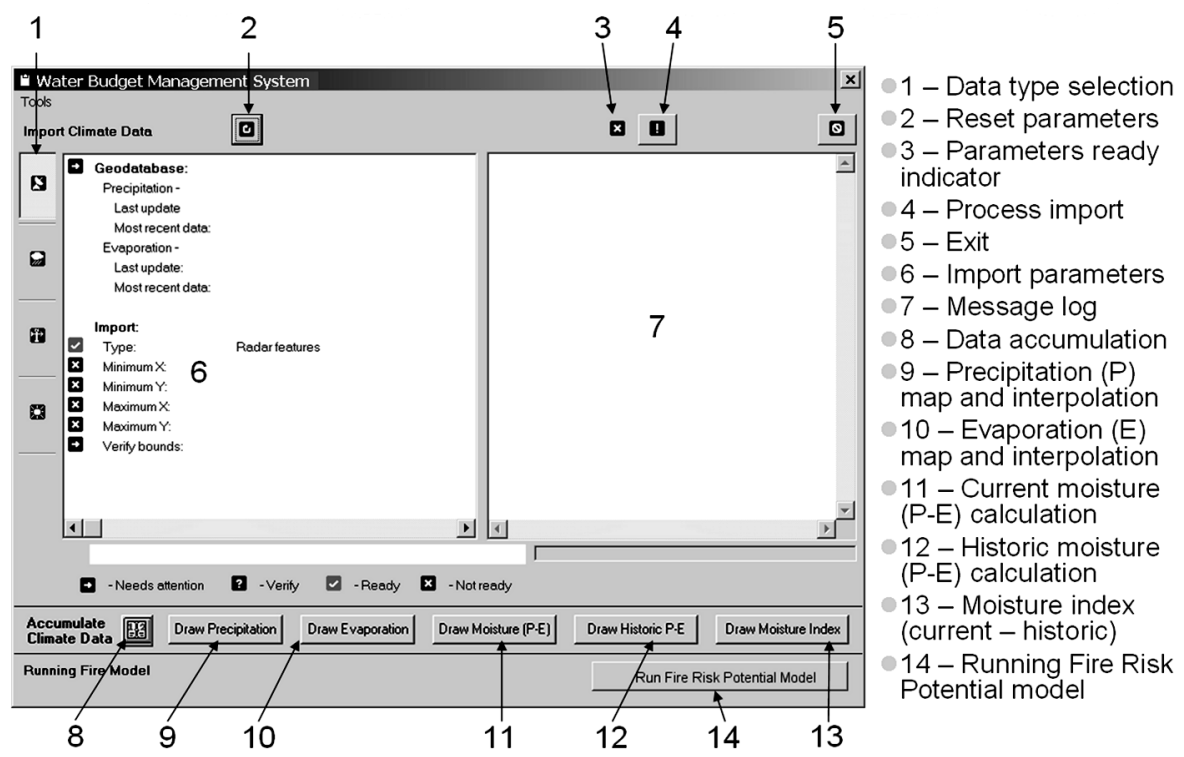

Fig. 5. A diagram illustrating the modules of the water budget management system (WBMS).

tables, radarLocation and StationLocations, respectively, by a one-to-one relationship. The regression formulas for evaporation calculation are stored in the evapCoeff table.

\section{Implementation of Water Budget Management System}

There are 14 procedures in the graphical user interface of the WBMS (Fig. 5). The upper part of the user interface (including procedures 1 to 7) is used for the climate data import module (see Fig. 3). The lower part of the user interface (including procedures 8 to 13 ) is used to accumulate climate data and calculate the water budget index. Procedure 14 (at the bottom of the user interface) is used to calculate the fire potential for the state of Mississippi.

\section{Coordinate Transformation}

Data for water budget calculations come from a variety of sources. Consequently, their various projections and coordinate systems must be unified. When importing new features, they are reprojected into a single projection (Mississippi State Transverse Mercator [MSTM] system) used throughout the geodatabase. The source projection is determined by the data provider and the projection employed in the geodatabase is used as the target projection.

While weather station data are presented in a standard geographic coordinate system, radar data are presented in a unique coordinate system known as HRAP. The HRAP coordinate system uses a secant polar stereographic projection with standard (true) latitude of $60^{\circ} \mathrm{N}$, a standard longitude (longitude of the coordinate system origin) of $105^{\circ} \mathrm{W}$, a false easting of -401 , and a false northing of -1601 . It also uses a 
spherical earth datum with a radius of $6,371.2 \mathrm{~km}$. Features in the HRAP coordinate system must first be transformed to a geographic coordinate system (GCS) before they can be reprojected to MSTM.

Weather station data and radar data obtained after 2006 are already in a GCS that is the source projection in projection transformation. The target projection is MSTM. Once both the source and target projections are defined, the feature class is projected.

\section{Data Population}

The climate data in the geodatabase is populated in one of two ways: ESRI's ArcObjects and Microsoft's ActiveX Data Objects (ADO). Feature classes contain spatial data that must be accessed through the interfaces in ArcObjects. Other standalone attribute tables in the geodatabase can be treated as any other database table and accessed using either ArcObjects or ADO.

The first step in creating a new feature is to set up the geometry type of the feature. This step involves setting the projection and coordinate system ("spatial reference") of the geometry, assigning an $x$ and $y$ value, and projecting the geometry into the target projection. The next step is to assign the geometry to a new feature. Then any additional fields available in the feature class can be populated (e.g., feature name). Finally, the feature is added to the feature class.

\section{MAPPING FIRE POTENTIAL: APPLICATION OF WATER BUDGET INDEX}

\section{Fire Potential Model for Mississippi}

Fire potential modeling requires consideration of various geospatial data. Morgan et al. (2001) compared several approaches for mapping fire regimes, including two rule-based approaches - a vegetation succession modeling approach and a statistical modeling approach for the Interior Columbia River Basin. Results of these comparisons show that fire frequency is related to four factors: climate, vegetation (fuels), anthropogenic influences (ignition), and topography (Morgan et al., 2001). Topography is an important fire variable in the western U.S., where changes in elevation and aspect are determinants of vegetation and climate. However, topography has less influence on fire risk potential in the eastern U.S. where topography is characterized by much gentler slopes (Zhai et al., 2003). Therefore, this study includes three primary weighted variables in the fire potential model for Mississippi: Climate (Water Budget), Ignition, and Fuel (Vegetation). Equation 4.1 illustrates the fire potential model developed in this study.

$$
\text { Fire potential }=w 1 \times \text { Climate }+w 2 \times \text { Fuel }+w 3 \times \text { Ignition, }
$$

where $w 1, w 2$, and $w 3$ are weighting factors and sum to 1 . Derivation of the climate variable is discussed above. Other model variables are discussed in detail below.

Fuels. Typically, fuel load is a relatively static or slowly changing variable; however, sudden changes in moisture conditions and substantial vegetation loss can contribute to rapid changes in fire potential. For the fuel component in this fire potential 
model, tree age and species data were acquired from the Forest and Wildlife Research Center at Mississippi State University. Collins et al. (2005) extracted tree age and species from Landsat MSS, TM, and ETM+ data at five-year intervals from 1973 to 2003. Tree age data for a species were calculated by post-classification comparison of temporally different Landsat data. For example, if an area classified as non-forested from Landsat MSS in 1973 and classified as pine trees from Landsat MSS, TM, and ETM+ in 1978 through 2003, the area was recorded as 26-30 years pine trees. The overall accuracy of the age and species product was $61 \%$. The accuracy is acceptable for this study considering the lack of reference data for classification accuracy assessment of early MSS and TM images. Tree age data include four classes: 10-19 years, 20-25 years, 26-30 years, and regeneration. Tree species association data include three classes: pine, mixed pine and hardwood, and hardwood. Combination of tree ages and species associations enabled derivation of 12 unique combinations. The resulting 12 classes were merged with the USGS land cover data (NLCD) in order to incorporate more detailed information about non-forested areas with the forested land cover information. The final results of the unique forest age/type group and non-forest combinations were assigned fire potential ranks ranging from 0 (no fire potential) to 5 (very high fire potential) (Fig. 6A).

Ignition. Anthropogenic factors play a major role in fire ignition in Mississippi. Humans affect wildfire ignition by altering the vegetative fuel load characteristics and by providing an ignition source (Pye et al., 2003; Petrakis et al., 2005). Human impacts on wildfire ignition can be measured by accessibility and interaction of human and forest. For accessibility to forest, Pye et al. (2003) demonstrated that proximity to roads and certain levels of road density were significantly correlated with increased fire potential. Gilreath (2006) showed that in Mississippi areas of moderate road density are at significantly higher potential. On the other hand, human interaction with forest can be measured by a gravity-based model. Sadasivuni (2007) tested the interaction among cities and medium-age (10 to 19 years) large contiguous pine forests for fire frequency relationships in Mississippi. The results of interaction of humans and forests showed that the areas of medium and low interaction have medium and low fire frequency, respectively, relative to fire occurrence. Therefore, to predict fire ignition, this study incorporates both human accessibility to forests and human interaction with forests. Human accessibility to forests is derived based on the level of roads (county, state, or interstate). Human interaction with forests is derived based on population size for cities and the distance of forests from those cities in Mississippi. The resulting ignition data are also assigned fire potential ranks ranging from 0 (no fire potential) to 5 (very high fire potential) (see Fig. 6B), which shows that the fire potential increases closer to roads and cities, particularly in areas characterized as the Wildland-Urban Interface (WUI). Since Mississippi has a humid climate, only $1.9 \%$ ( $0.5 \%$ lightning, $1.4 \%$ re-ignition) of all fires that required suppression in Mississippi over a 17-year fire record were non-anthropogenic in origin, based on the fire frequency data obtained from the MFC.

\section{Mapping with Fire Potential Model}

The fire potential was mapped using the fire potential model with three weighted variables: climate, fuel, and ignition. The water budget index (see the previous 

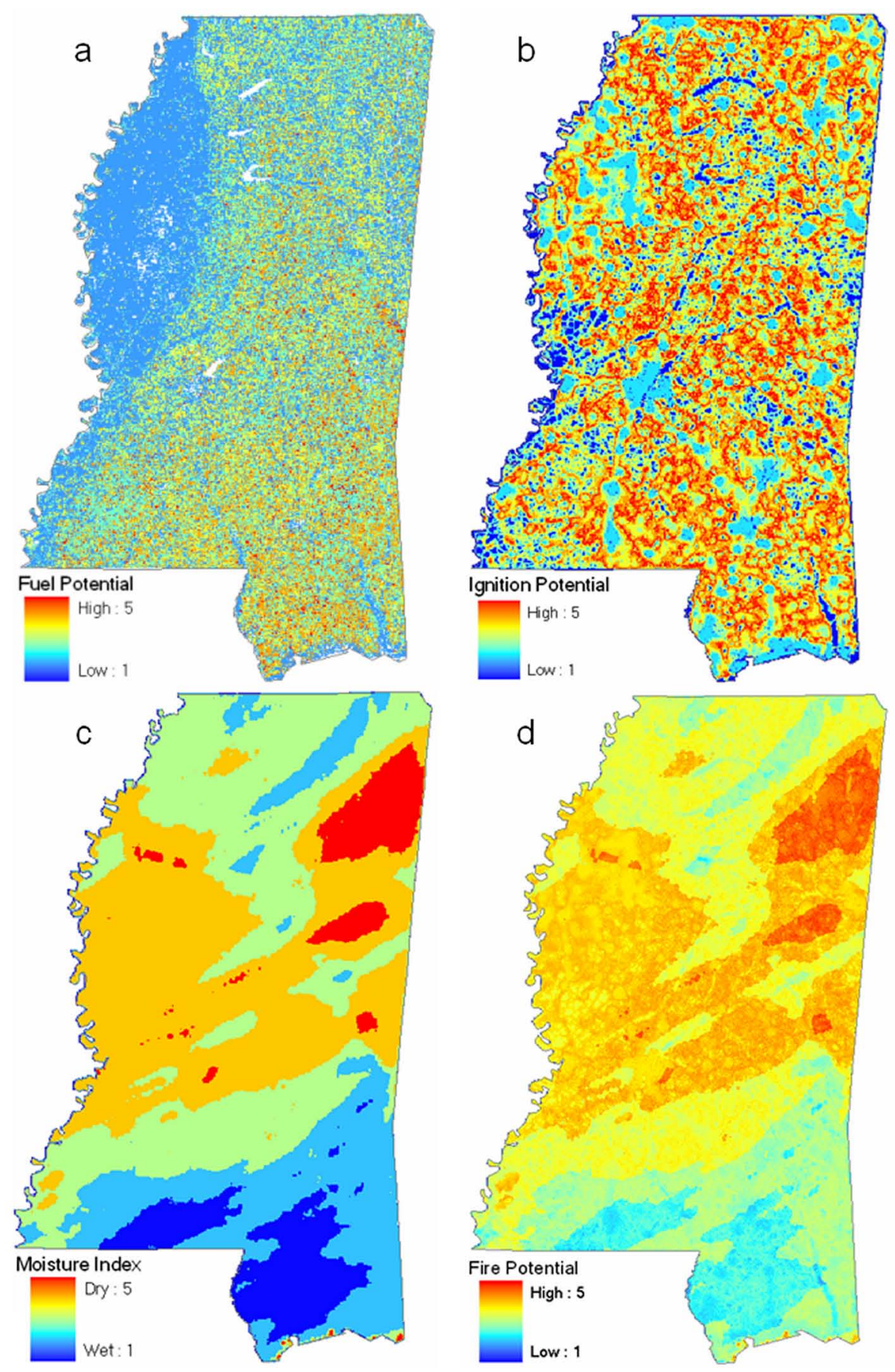

Fig. 6. Fire potential for the state of Mississippi in January 2008. 
subsection on "Regression for Evaporation") developed as part of this study was used for the climate component and is the focus of this paper. To incorporate these three variables into a single multi-criteria evaluation, we assigned different weights to each variable based the relative importance of each variable to fire potential. The fire potential model is re-calibrated January 1 of each year and is focused on describing fire potential for the late-summer/early-fall fire season. Fire frequency and size during this season are considered to be highly correlated with antecedent climatic conditions (Dixon et al., 2008). Consequently, the weights are 70\% to $w 1$ for climate, $20 \%$ to $w 2$ for fuel, and $10 \%$ to $w 3$ for ignition in the fire potential model (see Eq. 1). The resulting fire potential map for Mississippi is shown in Figure 6. For January 2008, the fire potential map shows very low fire potential in the southern coast area in Mississippi, because the water budget (P-E) is much higher than the average history water budget in the area during January. Most spatial depictions of areas of higher fire potential in Mississippi occur in areas that are drier that the average historic water budget at those locations.

\section{CONCLUSION}

In this study, a water budget management system (WBMS) was developed, which includes three modules: climate data importing, climate data accumulation and water budget index calculation, and fire potential mapping. In particular, the climate data importing module automates the data importing process including data projection, database creation, and data population. For data storage, ESRI's geodatabase was used to maintain spatio-temporal climate data consistently.

The water budget index calculation module derives a water budget index from precipitation and evaporation data. NEXRAD radar data provide precipitation at higher spatial density relative to weather station data. NEXRAD radar data have been shown to be better at characterizing precipitation, particularly in the summer, when rainfall is more convective in nature. Predicted and interpolated evaporation at weather station locations provides higher spatial density of evaporation estimates than interpolation of actual evaporation obtained from pan evaporation stations. Local measurements of precipitation and evaporation are used to derive descriptive water budgets (precipitation-evaporation). The water budgets are then compared to the 50year historic water budgets in order to derive a spatio-temporal water budget index that represents relative landscape moisture as compared to the historic average landscape moisture content.

Finally, as one application of the developed WBMS, a fire potential model was developed for Mississippi utilizing three weighted variables (fuel, ignition, and climate). The fuel data were derived from tree age and species models, while ignition data were derived from human accessibility to forest and human interaction with forest models. For the climate data, water budget indices were used as calculated in the WBMS. The resulting map of fire potential showed that the southern coastal area had lower fire potential overall in Mississippi, mainly because of higher values in water budget indices. The WBMS developed in this study can be used for any application that utilizes water budget information and may be applicable to mapping fire potential for the entire southeastern United States. 


\section{ACKNOWLEDGMENT}

This study has been supported by NASA through Integrated Systems Solution (ISS) grant NNS06AA72D under NASA's Applied Science Division.

\section{REFERENCES}

Bell, C. L., 2004, Synthesis of a Serially Complete and Homogeneous Evaporation Data Set for the Southeastern Region of the United States, Mississippi State, MS: Department of Geosciences, Mississippi State University.

Beven, K., 1979, "A Sensitivity Analysis of the Penman-Monteith Actual Evapotranspiration Estimates," Journal of Hydrology, 44:169-190.

Bruton, J. M., Hoogenboom, G., and R. W. McClendon, 2000, “A Comparison of Automatically and Manually Collected Pan Evaporation Data," Transactions of the ASAE, 43:1097-1101.

Collins, C. A., Wilkinson, D. W. and D. L. Evans, 2005, "Multi-temporal Analysis of Landsat Data to Determine Forest Age Classes for the Mississippi Statewide Forest Inventory-Preliminary Results," in Proceedings of the Third International Workshop on the Analysis of Multi-Temporal Remote Sensing Images, Biloxi, MS (CD-ROM).

Cooke, W. H., III, Grala, K., Evans, D., and C. Collins, 2007, “Assessment of preand post-Katrina Fuel Conditions as a Component of Fire Potential Modeling for Southern Mississippi," Journal of Forestry, 105(8):389-397.

Cooke, W. H., III, Grala, K., and C. L. Wax, 2008, "A Method for Estimating Pan Evaporation for Inland and Coastal Regions of Southeastern U.S.," The Southeastern Geographer, 48(2):149-171.

Dixon, P. G., Goodrich, G. B., and W. H. Cooke, 2008, "Using Teleconnections to Predict Wildfires in Mississippi," Monthly Weather Review, 136(7):2804-2811.

Gilreath, J. M., 2006, Validation of Variables for the Creation of a Descriptive Fire Risk Potential Model for the Southeastern Fire District of Mississippi, M.S. thesis, Department of Geosciences, Mississippi State University.

Jones, F. E., 1992, Evaporation of Water: With Emphasis on Applications and Measurements, Chelsea, MI: Lewis Publishers.

Lindsey, S. D. and R. K. Farnsworth, 1997, "Sources of Solar Radiation Estimates and Their Effect on Daily Potential Evaporation for Use in Streamflow Modeling," Journal of Hydrology, 201:348-366.

Monteith, J. L., 1965, "Evaporation and Environment," Symposia of the Society for Experimental Biology, 19:205-234.

Morgan, P., Hardy, C. C., Swetnam, T. W., Rollins, M. G., and D. G. Long, 2001, "Mapping Fire Regimes across Time and Space: Understanding Coarse and FineScale Fire Patterns," International Journal of Wildland Fire, 10:329-342.

Morris, J. A., 2007, An Analysis of the Keetch-Byram Drought Index as a Predictor of Forest Fire Risk Potential, M.S. thesis, Department of Geosciences, Mississippi State University

Petrakis, M., Psiloglou, B., Lianou, M., Keramitsoglou, I., and C. Cartalis, 2005, "Evaluation of Forest Fire Risk and Fire Extinction Difficulty at the Mountainous 
Park of Vikos-Aoos, Northern Greece: Use of Remote Sensing and GIS Techniques," International Journal of Risk Assessment and Management, " 5: 50-65.

Pye, J. M., Prestemon, J. P., Butry, D. T., and K. L. Abt, 2003, "Prescribed Burning and Wildfire Risk in the 1998 Fire Season in Florida," in Proceedings RMRS-P29 of Fire, Fuel Treatments, and Ecological Restoration Conference, Fort Collins, CO: U.S. Department of Agriculture, Forest Service, Rocky Mountain Research Station [http://www.fs.fed.us/rm/pubs/rmrs_p029_015_026.pdf].

Sadasivuni, R., 2007, Gravity Model to Detect Forest Fire-Prone Areas in the Southeast Fire District of Mississippi, M.S. thesis, Department of Geosciences, Mississippi State University

Sumner, D. M. and J. M. Jacobs, 2005, "Utility of Penman-Monteith, Priestley-Taylor, Reference Evapotranspiration, and Pan Evaporation Methods to Estimate Pasture Evapotranspiration," Journal of Hydrology, 308:81-104.

WMO (World Meteorological Organization), 2008, Status of Individual Statements of Guidance (SOGs) and Recommended Update Strategy: Hydrology and Water Resources, Geneva, Switzerland: World Meteorological Organization [www .wmo.int/pages/prog/www/OSY/Meetings/ET-EGOS_Geneva2008/documents/ Doc.7.2.7.doc], last accessed December 3, 2008.

Zhai, Y. S., Munn, I. A., and D. L. Evans, 2003, "Modeling Forest Fire Probabilities in the South Central United States using FIA Data," Southern Journal of Applied Forestry, 27(1):11-17. 